\title{
LOOPOGRAPHY EXAMINATION FOR COLON CANCER CASES IN TANGERANG DISTRICT PUBLIC HOSPITAL
}

\author{
Gando Sari ${ }^{1)}$, Triana Retno Putri ${ }^{1)}$, Samsun ${ }^{1)}$, Sriyatun ${ }^{1)}$, Nursama Heru' \\ ${ }^{1}$ Politeknik Kesehatan Kementerian Kesehatan Jakarta II, J1. Hang Jebat III Kebayoran \\ Baru, Jakarta Selatan, Kode Pos 12120 \\ E-mail: bundagandosari@ gmail.com
}

Submitted: 16 October 2019 ; Accepted: 12 November 2019

https://doi.org/10.36525/sanitas.2019.12

\begin{abstract}
Loopography examination technique is a radiological examination technique in lower digestive tract (colon) by inserting a positive contrast media into the colon through an artificial hole in abdominal area. This examination aims to evaluate the anatomy and physiology function from distal section of colon to anus in patients with colon cancer. This research was conducted in radiology installation of Tangerang District Public Hospital from November to December 2018, using a qualitative descriptive method with a literature study approach and interview. The results found that loopography examination in Tangerang District Public Hospital did not require special preparation. The kind of contrast media used is a water-soluble contrast media such as iohexol with a ratio of 1: 3 mixed with $\mathrm{NaCl}$. This loopography contrast media can be inserted through the clean stoma or anal. The routine projections performed for loopography examination in Tangerang District Public Hospital are Plan photos of Abdomen, Antero Posterior (AP) and Lateral. But sometimes Oblique projection is also used as an addition if there is less obvious anatomy due to overlap/superposition.
\end{abstract}

Keywords: loopography, colon cancer, water soluble-contrast media

This is an open access journal, and articles are distributed under the terms of the Creative Commons Attribution-NonCommercial-ShareAlike 4.0 License, which allows others to remix, tweak, and build upon the work non-commercially, as long as appropriate credit is given and the new creations are licensed under the identical terms.

C2019 Sanitas

\section{PEMERIKSAAN LOOPOGRAFI UNTUK KASUS KANKER KOLON DI RSU KABUPATEN TANGERANG}

\begin{abstract}
ABSTRAK
Teknik pemeriksaan loopografi adalah teknik pemeriksaan secara radiologis pada saluran pencernaan bagian bawah (colon) dengan memasukkan media kontras positif ke dalam colon melalui lubang buatan pada daerah abdomen. Pemeriksaan ini bertujuan untuk mengevaluasi fungsi anatomi dan fisiologi dari colon bagian distal hingga ke anus pada kondisi klinis kanker kolon. Penelitian ini dilakukan di Instalasi radiologi RSU Kabupaten Tangerang pada bulan November sampai dengan Desember 2018, menggunakan metode deskriptif kualitatif dengan pendekatan studi pustaka dan wawancara. Hasil penelitian menunjukkan bahwa pemeriksaan loopografi di RSU Kabupaten Tangerang tidak memerlukan persiapan khusus. Jenis kontras yang digunakan yaitu jenis kontras media yang bersifat water soluble seperti iohexol dengan takaran 1 : 3 yang dicampurkan $\mathrm{NaCl}$. Pemasukan bahan kontras loopografi ini dapat melalui stoma bersih atau anal. Proyeksi rutin yang dilakukan untuk pemeriksaan loopografi di RSU Kabupaten Tangerang adalah Plan foto Abdomen, Antero Posterior (AP)
\end{abstract}


SANITAS: JURNAL TEKNOLOGI DAN SENI KESEHATAN

dan Lateral. Namun pada kasus tertentu terkadang juga perlu memakai proyeksi Oblique sebagai tambahan jika ada anatomi yang kurang terlihat jelas karena overlap/superposisi.

Kata Kunci : Loopografi, kanker kolon, kontras media larut air

\section{PENDAHULUAN}

Saat ini ilmu pengetahuan dan teknologi semakin berkembang khususnya pada bidang kesehatan ataupun kedokteran. Hal ini dapat kita lihat dari perkembangan teknologi pada bidang radiologi. Sejak ditemukannya sinar-X pada tahun 1895 oleh Wilhelm Conrad Roentgen, pemanfaatannya disegala bidang semakin terus berkembang (1). Pemeriksaan radiologi merupakan salah satu pemeriksaan yang amat diperlukan dalam menegakkan diagnosa suatu penyakit (2). Ada tiga tipe umum pemeriksaan X-ray yaitu radiografi, fluoroskopi, dan computed tomography (3). Fluoroskopi adalah suatu alat yang digunakan untuk studi visual jatuhnya bayangan laten dari tabir fluoroskopi menjadi bayangan permanen pada film, dalam aplikasi medik fluoroskopi digunakan untuk memvisualisasikan gerakan dari struktur-struktur internal (4). Salah satu pemanfaatan yang menggunakan fluoroskopi yakni untuk pemeriksan loopografi.

Pemeriksaan radiologi pada sistem digestivus dapat dibagi atas 2 golongan besar, yaitu pemeriksaan dengan kontras dan pemeriksaan tanpa kontras (5). Loopografi merupakan teknik pemeriksaan radiografi pada saluran pencernaan bagian bawah (colon) dengan menggunakan kontras media positif yang dimasukkan ke dalam stoma pada dinding abdomen (6).

Pada pemeriksaan loopografi menggunakan kontras media jenis water soluble, kontras media jenis water soluble mudah diserap oleh tubuh dan tidak mengakibatkan banyak komplikasi (7), sebelum digunakan kontras media terlebih dahulu dicampur $\mathrm{NaCl}$ atau aquades dengan perbandingan yaitu 1:3 (8).

Pemeriksaan radiodiagnostik secara garis besar dibagi menjadi 2, yaitu pemeriksaan rutin dan pemeriksaan khusus. Teknik pemeriksaan yang tidak memerlukan persiapan khusus, lebih cepat dan sederhana disebut teknik pemeriksaan rutin. Sedangkan teknik pemeriksaan yang memerlukan persiapan-persiapan seperti persiapan pasien, persiapan alat dan bahan 
SANITAS: JURNAL TEKNOLOGI DAN SENI KESEHATAN

disebut pemeriksaan khusus. Pada pemeriksaan loopografi, perlu dilakukan persiapan terlebih dahulu pada pasien anak dan dewasa, seperti puasa atau pengosongan colon. Sedangkan persiapan pasien tidak dilakukan pada pasien bayi (9).

Kasus yang sering ditemukan pada pemeriksaan loopografi yakni colostomy dan ileostomy. Colostomy adalah pembuatan lubang atau stoma secara bedah di antara dua bagian dari usus besar yang dimaksudkan sebagai pengganti tempat pengeluaran faeces (10) (11). Para penderita colostomy seringkali membutuhkan saran-saran ahli untuk hidup secara wajar dan nyaman. Kebanyakan rumah sakit besar mempunyai perawat terlatih yang disebut stomatherapis yang bisa membantu dalam hal ini (12).

Ada beberapa indikasi dilakukannya colostomy yaitu dugaan pada klinis hirschprung, colon cancer, malformasi anorektal dan fistula pada atresia ani. Di Indonesia, didapatkan angka yang sedikit berbeda dengan laporan dari negara barat karena terdapat kecenderungan terkena serangan kanker lebih banyak untuk umur yang lebih muda. Untuk usia di bawah 40 tahun data dari Bagian Patologi Anatomik FKUI didapatkan angka 35,625\% (13). Karsinoma colon, biasanya suatu adenokarsinoma, merupakan keganasan saluran pencernaan yang paling umum, dengan jaringan yang abnormal (lesi) lebih besar pada daerah rektosigmoid (14).

Pada pemeriksaan loopografi dengan klinis ca colon di RSU Kabupaten Tangerang ini memasukkan kontras media melalui stoma bersih pada dinding abdomen. Pemeriksaan ini bertujuan untuk mengevaluasi fungsi anatomi dan fisiologi dari colon bagian distal hingga ke anus. Dan kontras media yang digunakan adalah jenis water soluble dengan posisi pemeriksaan yang digunakan yaitu $A P$, Lateral dan penambahan posisi Oblique jika ada anatomi yang kurang jelas terlihat disertai pengambilan gambar radiografi menggunakan pesawat fluoroskopi.

Masalah yang akan dibahas pada penelitian ini adalah bagaimana prosedur pemeriksaan loopografi dengan pada kasus kanker kolon di RSU Kabupaten Tangerang. Penelitian ini bertujuan untuk menjelaskan teknik pemeriksaan loopografi. 
SANITAS: JURNAL TEKNOLOGI DAN SENI KESEHATAN

\section{METODE PENELITIAN}

Metode yang digunakan dalam penelitian ini adalah deskriptif kualitatif. Dalam pengumpulan data penulis melakukan observasi di Instalasi Radiologi RSU Kabupaten Tangerang, pada bulan November sampai dengan bulan Desember 2018. Penelitian ini menggunakan dua buah sampel dari seluruh pasien pemeriksaan loopografi dengan kondisi klinis kanker kolon di Instalasi Radiologi RSU Kabupaten Tangerang.

Metode pengumpulan data yang digunakan adalah observasi yaitu pengambilan data dengan melakukan pengamatan secara langsung dan mencatat hasil pengamatan tersebut pada lembar kerja yang berhubungan dengan masalah penelitian.

Instrumen penelitian yang digunakan adalah lembar kerja yang digunakan untuk mencatat data yang diperoleh pada saat melakukan observasi, dan kamera alat untuk dokumentasi saat observasi.

\section{HASIL DAN PEMBAHASAN}

Pemeriksaan loopografi dengan kondisi klinis kanker kolon di Instalasi Radiologi RSU Kabupaten Tangerang dilakukan dengan mendeskripsikan teknik berdasarkan observasi dan wawancara radiolog serta radiografer.

Prosedur pertama yang dilakukan adalah pasien datang ke bagian administrasi Instalasi Radiologi RSU Kabupaten Tangerang untuk mendaftar pemeriksaan loopografi disertai dengan surat rujukan dokter, kemudian pasien dibuatkan jadwal pemeriksaan dan menerima formulir tindak radiologi.

Pemeriksaan loopografi dengan kondisi klinis kanker kolon di RSU Kabupaten Tangerang tidak memerlukan persiapan khusus, dikarenakan pada pemeriksaan loopografi ini kontras dimasukkan melalui stoma bersih (stoma distal). Pemeriksaan loopografi ini hanya untuk mengevaluasi fungsi anatomi dan fisiologi dari colon bagian distal hingga ke anus, selama tidak digunakan (diblok) dalam evakuasi faeces. Pasien hanya diinstruksikan untuk membawa colostomy bag untuk mengganti colostomy bag yang sudah terpasang pada saat selesai pemeriksaan. Berbeda dengan menurut teori (9) pemeriksaan loopografi 
SANITAS: JURNAL TEKNOLOGI DAN SENI KESEHATAN

menggunakan persiapan khusus seperti puasa dan pengosongan colon sebelum dilakukannya pemeriksaan.

Prosedur selanjutnya dilakukan pengisian inform consent yang disetujui oleh pasien/ keluarga pasien untuk dilakukannya pemeriksaan loopografi dengan penggunaan bahan kontras dan petugas memberikan penjelasan tentang tata cara pelaksanaan tindak radiologi.

Alat dan bahan yang digunakan dalam pemeriksaan loopografi di Instalasi Radiologi RSU Kabupaten Tangerang yaitu pesawat DR dengan fluoroskopi, bahan kontras jenis water soluble, $\mathrm{NaCl}$, kateter balon No.16, spuit $50 \mathrm{cc}$, dan marker. Berdasarkan wawancara dengan Radiografer RSU Kabupaten Tangerang bahwa pemeriksaan loopografi menggunakan bahan kontras yang bersifat water soluble dicampurkan $\mathrm{NaCl}$ dengan perbandingan 1 : 3 yang bertujuan untuk mengurangi konsentrasi dari kontras agar tidak terlalu pekat dan tidak mengurangi hasil gambaran.

Menurut teori (6) pemeriksaan loopografi juga bisa menggunakan bahan kontras media positif lainnya seperti barium sulfat. Namun, menurut hasil wawancara di RSU Kabupaten Tangerang alasan pemeriksaaan loopografi ini tidak menggunakan barium sulfat karena pada saat dilakukan pemeriksaan tidak tersedia barium sulfat dan pasiennya pasca operasi dikhawatirkan terjadinya perlengketan, selain itu kontras media yang bersifat water soluble juga lebih mudah di-eksresikan oleh tubuh.

Menurut hasil wawancara radiografer pemeriksaan diawali dengan pemasangan marker. Kemudian, lakukan plan foto abdomen dengan proyeksi Antero Posterior (AP) yang bertujuan untuk melihat kondisi colon secara keseluruhan dan untuk pengaturan faktor eksposi. Setelah itu, dengan menggunakan kateter yang dihubungkan dengan spuit 50 cc yang berisi kontras pada Ny. S (sampel pertama) dimasukan melalui stoma bersih dan pada Tn. M (sampel kedua) dimasukkan melalui anal karena pada saat pengerjaan tidak terlihat atau kemungkinan terselipnya stoma bersih pada colostomy sehingga diputuskan untuk memasukkan kontras media melalui anal. Banyaknya kontras yang digunakan tergantung dari panjangnya colon. 
SANITAS: JURNAL TEKNOLOGI DAN SENI KESEHATAN

Proyeksi rutin yang dilakukan untuk pemeriksaan loopografi di RSU Kabupaten Tangerang AP dan Lateral, proyeksi Oblique digunakan jika ada gambaran anatomi yang kurang terlihat. Proyeksi AP dilakukan untuk melihat kontras media mengisi colon secara keseluruhan. Proyeksi Oblique dilakukan untuk melihat apabila ada anatomi colon yang tidak terlihat karena overlap/ superposisi. Dan proyeksi Lateral dilakukan untuk melihat bagian rectum dan sigmoid selain itu juga dapat melihat keluarnya kontras melalui anus.

Berdasarkan hasil penelitian pada pasien Ny.S usia 46 tahun dan Tn. M usia 36 tahun di RSU Kabupaten Tangerang didapatkan hasil sebagai berikut:

1. Foto Plan Abdomen

Posisi Pasien : Supine di atas meja pemeriksaan.

Posisi Obyek : Posisi pasien diatur simetris dan true antero posterior.

Central Ray $\quad$ : Vertikal tegak lurus pada film.

Central Point $\quad$ : Dipertengahan kedua crista iliaca.

Hasil Gambaran :

a. Hasil gambaran pada foto pendahuluan Ny. S (sampel pertama) tampak gambaran marker pada stomata kotor di bagian lateralis dan stomata bersih dibagian medialis dari sisi kanan tubuh pasien (sisi colon ascendens). Tampak symphisis pubis tidak terpotong, dan batas kedua sisi lateral abdomen tidak terpotong dan bagian atasnya tampak dinding diafragma (pada Gambar 1. sebelah kiri).

b. Hasil gambaran pada foto pendahuluan Tn. M (sampel kedua) Tampak symphisis pubis tidak terpotong, dan batas kedua sisi lateral abdomen tidak terpotong dan bagian atasnya tampak dinding diafragma dan tidak diberikan marker karena pemasukan kontras medianya akan melalui anal, selain itu pemasangan marker juga tergantung pada permintaan dokter (pada Gambar 1. sebelah kanan). 
SANITAS: JURNAL TEKNOLOGI DAN SENI KESEHATAN

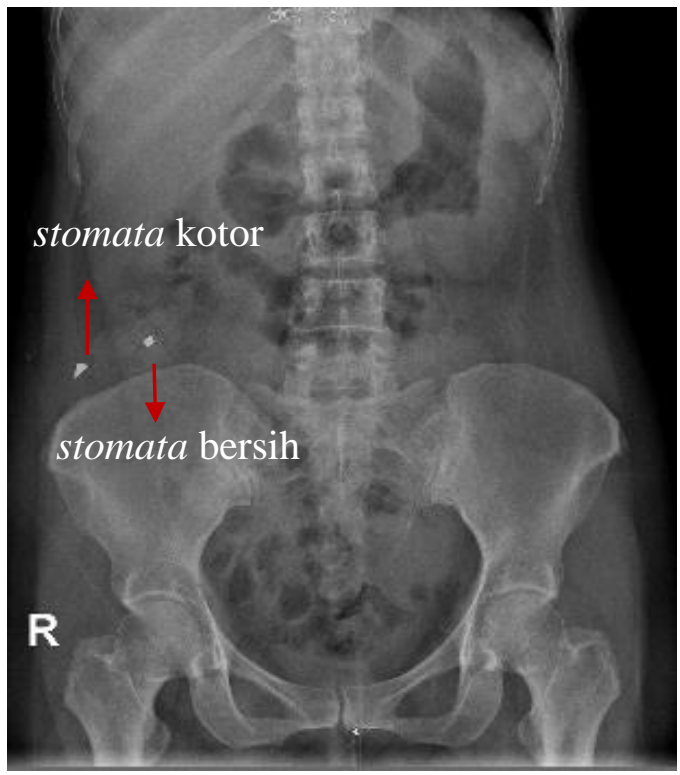

(Ny. S)

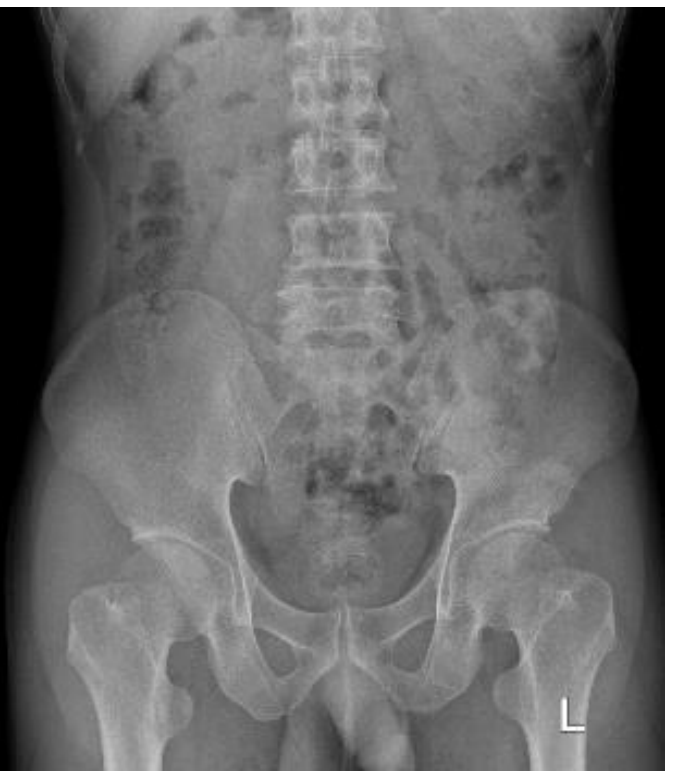

$(\mathrm{Tn}, \mathrm{M})$

Gambar 1. Foto Pendahuluan Abdomen Proyeksi AP (Radiologi RSU Kab. Tangerang, 2019)

2. Antero Posterior

Posisi Pasien : : Supine di atas meja pemeriksaan.

Posisi Obyek $\quad$ : Posisi pasien diatur simetris dan true antero posterior.

Central Ray : : Vertikal tegak lurus pada film.

Central Point $\quad$ : Di pertengahan kedua crista iliaca.

Kontras Media $\quad$ : Banyaknya kontras yang dimasukan tergantung panjang

dari colon.

Hasil Gambaran setelah pemasukan bahan kontras media:

a. Hasil gambaran setelah pemasukan bahan kontras media pada Ny. S (sampel pertama), tampak kontras media mengisi ileum, colon ascenden, flexura hepatika, colon tranversum, flexure lienalis, colon descenden, sigmoid hingga rectum (pada Gambar 2. sebelah kiri). 
b. Hasil gambaran setelah pemasukan bahan kontras media pada Tn. M (sampel kedua), tampak kontras media mengisi daerah colon descendens dan rectosigmoid (pada Gambar 2. sebelah kanan).

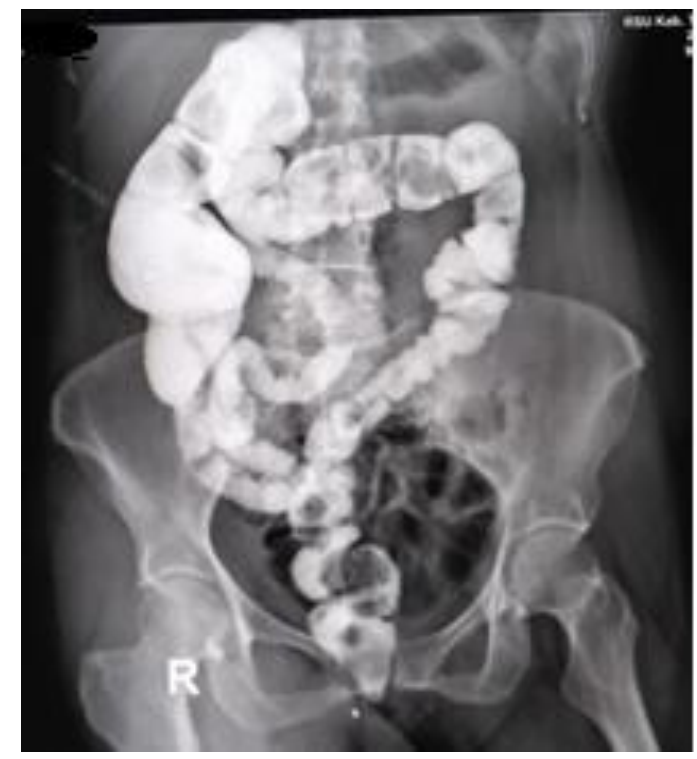

(Ny. S)

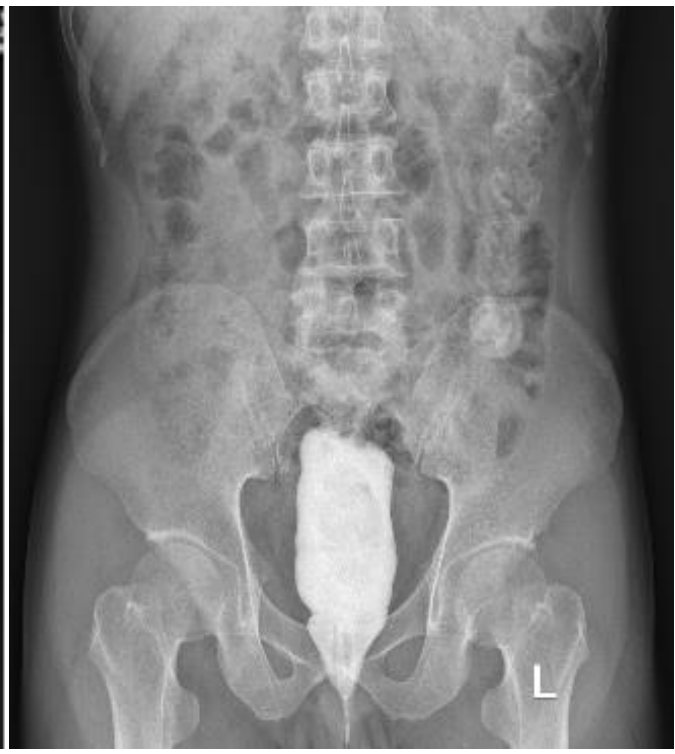

(Tn, M)

Gambar 2. Proyeksi AP Dengan Kontras Media (Radiologi RSU Kab. Tangerang, 2019)

3. Lateral

Posisi Pasien

Posisi Obyek

Central Ray

Central Point

Hasil Gambaran
: Recumbent dengan salah satu sisi tubuh di atas meja

: Posisikan pasien dengan Mid Coronal Plane (MCP) terletak di pertengahan garis meja pemeriksaan.

: Vertikal tegak lurus pada film.

: Spina Iliaca Anterior Superior (SIAS).

: Tampak proyeksi lateral yang terdapat pada gambar 3. kedua sampel tampak kontras mengisi colon tanpa ditemukan tumor. Pasien sudah dilakukan tindakan operasi pengangkatan tumor (pasca operasi). 


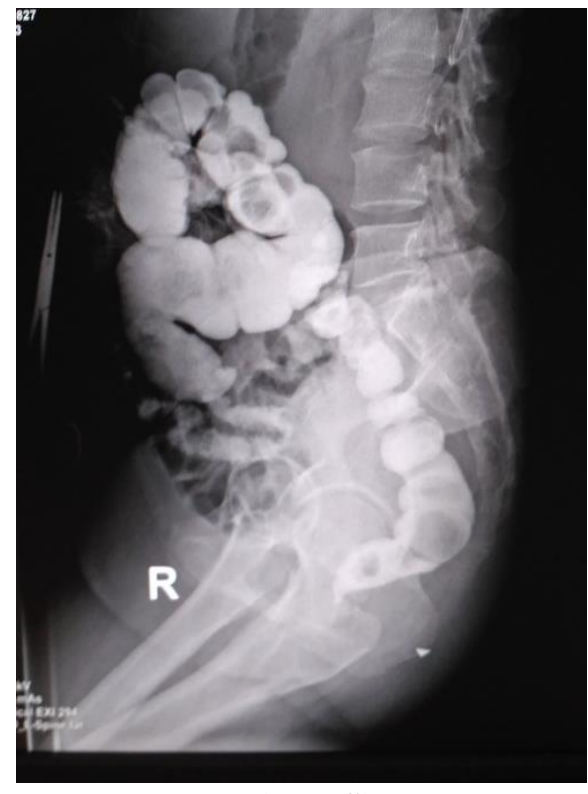

(Ny. S)

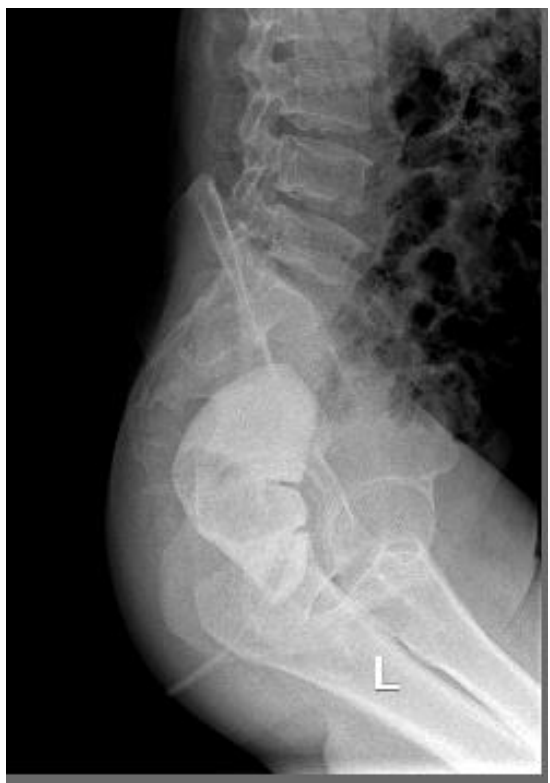

$(\mathrm{Tn}, \mathrm{M})$

Gambar 3. Proyeksi Lateral Dengan Kontras Media (Radiologi RSU Kab. Tangerang, 2019)

Hasil gambaran yang terdapat pada gambar 2. pada Ny. S (sampel pertama) tampak kontras mengisi seluruh colon termasuk fleksura, dan colon sigmoid dan pada Tn. M (sampel kedua) kontras mengisi daerah colon descendens dan rectosigmoid. Pada gambar Ny. S (sampel pertama) terlihat jalan masuknya kontras lebih panjang dibanding Tn. M (sampel kedua), karena letak colostomy pada Ny. S (sampel pertama) terletak di daerah colon ascendens, sedangkan pada Tn. M (sampel kedua) terletak di daerah sekitar colon descendens.

\section{SIMPULAN}

Pada pemeriksaan loopografi dengan kondisi klinis kanker kolon di RSU Kabupaten Tangerang tidak diperlukannya persiapan khusus, karena pemeriksaan ini dilakukan hanya untuk mengevaluasi fungsi anatomi dan fisiologi dari colon bagian distal hingga ke anus. Pasien hanya diinstruksikan membawa colostomy bag untuk mengganti colostomy bag yang sudah terpasang pada saat selesai pemeriksaan. Kemudian, pemasukan kontras media pada 
SANITAS: JURNAL TEKNOLOGI DAN SENI KESEHATAN

pemeriksaan loopografi bisa melalui stomata maupun anal. Pemasukan kontras melalui anal biasanya dilakukan karena hanya ada satu lubang stoma saja yaitu stomata kotor. Proyeksi yang digunakan pada pemeriksaan loopografi di RSU Kabupaten Tangerang dengan klinis kanker kolon adalah plan foto abdomen AP supine, AP dan Lateral pada saat dimasukkannya kontras. Terkadang juga dipakai proyeksi Oblique apabila ada anatomi yang kurang jelas terlihat karena adanya superposisi. Hasil gambaran loopografi bergantung pada teknik radiografi yang dilakukan sesuai dengan letak area dari colostomy, bisa lebih superior atau inferior.

\section{DAFTAR PUSTAKA}

1. Sari FM, Suryono. Pengukuran Linieritas Tingkat Keabuan (Gray Level) Citra Fluoroskopi Menggunakan Metode Pengolahan Citra Digital. Youngster Phys J. 2014;3:279-84.

2. Yueniwati Y. Prosedur Pemeriksaan Radiologi untuk Mendeteksi Kelainan dan Cedera Tulang Belakang. Malang: UB Press; 2014.

3. Bushong SC. Radiologic Science for Technologists. St. Louis, Missouri: Elsevier; 2017.

4. Artitin C, Harahap WA, Ellyanti A. Pengukuran Dosis Radiasi Pada Organ Tiroid dan Mata Saat Pemeriksaan Fluoroskopi. J Kesehat Andalas. 2018;

5. Rasad S. Radiologi Diagnostik. Edisi-2. Jakarta: BPFKUI; 2005.

6. Tamaela LA, Pramuljo HS, Bermanshah EI. Radiologi Anak. Edisi I. Jakarta: Badan Penerbit IDAI; 2010.

7. Speck U. X-Ray Contrast Media. Berlin: Bayer AG; 2018.

8. Lakhar BN. Radiological Procedures \{ A Guideline ). Edition-3. Karol Bagh - New Delhi: Arya Publications; 2017.

9. Long BW, Rollins JH, Smith BJ. Merrill 'S Atlas of Radiographic Positioning \& Gando Sari, Triana Retno Putri, Samsun, Sriyatun, Nursama Heru | 126 
SANITAS: JURNAL TEKNOLOGI DAN SENI KESEHATAN

Procedures. Edition-13. St. Louis, Missouri: Elsevier; 2016.

10. Pearce EC. Anatomi dan Fisiologi untuk Paramedis. Jakarta: PT Gramedia Pustaka Utama; 2011.

11. Lampignano JP, Leslie E. Kendrick. Bontrager's Text Book of Radiographic Positioning and Related Anatomy. Edition-9. St. Louis, Missouri: Elsevier Inc; 2018.

12. Irianto K. Anatomi dan Fisiologi untuk Mahasiswa. Bandung: Alfabeta; 2012.

13. Sudoyo AW, Setiyohadi B, Alwi I, K MS, Setiati S. Buku Ajar Ilmu Penyakit Dalam Jilid 1. Edisi-5. InternaPublishing; 2010.

14. Patel PR. Lecture Notes: Radiology. Edition-3. London: Willey Blackwell; 2010. 